\title{
Corrigendum: Influenza virus mRNA trafficking through host nuclear speckles
}

Amir Mor, Alexander White, Ke Zhang, Matthew Thompson, Matthew Esparza, Raquel Muñoz-Moreno, Kazunori Koide, Kristen W. Lynch, Adolfo García-Sastre and Beatriz M. A. Fontoura

Nature Microbiology 1, 16069 (2016); published online 27 May 2016; corrected 9 January 2017

In the version of this Article originally published, an additional National Institute of Health grant (NIH R21 AI119304) should have been acknowledged for the authors A.G.-S. and B.M.A.F. This has been corrected in all versions of the Article. 